\title{
Evaluating railway track support stiffness from trackside measurements in the absence of wheel load data
}

Authors: Louis Le Pen ${ }^{1}$, David Milne ${ }^{1}$, David Thompson ${ }^{2}$, William Powrie $^{1}$

Affiliations:

${ }^{1}$ University of Southampton, Infrastructure Research Group, University Road, Highfield, Southampton, UK

${ }^{2}$ University of Southampton, Institute of Sound and Vibration Research, University Road, Highfield, Southampton, UK

Email addresses: Ilp@soton.ac.uk,d.milne@soton.ac.uk, djt@isvr.soton.ac.uk, wp@soton.ac.uk

Corresponding author: Louis Le Pen, Tel: +44(0)23 80592883

The article was accepted for publication by the Canadian Geotechnical Journal (http://www.nrcresearchpress.com/journal/cgj) on 18 February 2016. An online version ahead of print has been given a DOI for citation purposes as:

- $10.1139 / \mathrm{cgj}-2015-0268$

The advance online version is available at the following permanent link: http://dx.doi.org/ 


\begin{abstract}
It is generally accepted that track support stiffness is a major factor controlling rates of track geometry deterioration, particularly where the track support stiffness changes abruptly. There is, therefore, considerable potential benefit in being able to quantify and detect changes in the track support stiffness. In recent years, trackside techniques using various types of transducer have been developed to determine track deflections as trains pass. However, deducing the track support stiffness from these measurements requires assumptions to be made concerning train loading and track behaviour, and scope for different interpretations remains. For example, loads from moving trains vary dynamically and it is not usually feasible to measure their exact values at any given point along the track. This paper presents new methods of analysis, which can be applied to frequency spectra of track displacement, velocity or acceleration generated as trains pass to calculate the track support stiffness for trains of known axle intervals, without needing to know the actual loads applied. The approach is demonstrated with reference to theory and measured data from a range of field sites.
\end{abstract}

\title{
Introduction
}

Maintenance of ballasted railway tracks is a major cost for railway infrastructure owners worldwide. In many countries, most of the railway infrastructure is mature and was built using methods, materials and to performance requirements that may have been superseded. This, together with increased demands being placed on networks, can lead to the development or exacerbation of localised trackbed problems, resulting in disproportionate levels of maintenance and associated costs, especially (but not exclusively) at switches and crossings and at transitions between softer and firmer supports. Identifying where and understanding why short lengths of track are not performing well and applying more cost-effective preventive maintenance has the potential to reduce costs in the medium- to long-term. For this purpose, new techniques for track performance measurement suitable for routine deployment at known problem locations are required.

It is becoming generally accepted that the track support stiffness is a major factor controlling rates of track geometry deterioration, particularly where the track support stiffness changes abruptly. In service measurements of track deflections can be used to determine the support stiffness, provided that the axle load at the point of measurement is known or can be estimated. This can be difficult or expensive to achieve in practice.

This paper presents a new method of track support stiffness evaluation based on the use of Fourier transforms of trackside measurement data, interpreted using a beam on an elastic foundation model of track behaviour. The major advantage of the approach is that knowledge of the locally varying applied dynamic load is not required.

\section{Background}

Although track movements are strictly elasto-plastic, the component of in-cycle plastic deformation after the initial few thousand loading cycles, during which the track beds in, is very small, in the order of $10^{-4} \mathrm{~mm}$ per train on normally operating track (Abadi, 2015, 
Shenton 1984). In contrast the recoverable or elastic deflection per cycle may be between $0.5 \mathrm{~mm}$ and $2 \mathrm{~mm}$. Thus for practical purposes the behaviour of the track over the few tens of cycles typically associated with a single train passage can reasonably be modelled as purely elastic. For many types of analyses, a typical railway track system can be idealised as comprising beams (the rails) on elastic supports representing the railpad, sleeper, ballast, sub-ballast and subgrade or formation, either lumped together or as separate springs connected in series beneath the rail (see, for example, Grassie and Cox, 1984; Esveld, 2001; RSSB, 2005). Although this is a simplification, it can provide useful insights into track performance. The support stiffness under the rail comprises a component due to the rail pad and a component due to the trackbed (ballast, subballast and subgrade). These components can be termed respectively the sleeper support stiffness $(\mathrm{MN} / \mathrm{m})$ and the rail pad stiffness $(\mathrm{MN} / \mathrm{m})$. Combining them in series gives the system support stiffness. Expressing each as a stiffness per unit length of track gives the equivalent support modulus $\left(\mathrm{MN} / \mathrm{m}^{2}\right)$ with the system support modulus representing the combined trackbed and pad behaviour as seen by the rail. While several definitions of track support stiffness could be justified, this paper will focus on that mathematically defined based on a beam (the rails) on a lumped elastic support; this will be termed the system modulus.

The system modulus only becomes relevant in relation to the ride quality experienced by the train and passengers and the safe operation of the train when it changes along the track. This is because a wheel exerting a constant load will always sit within the deflected profile of the rail. Thus the system stiffness or modulus will not affect the train except when either it or the load changes, causing variations in the deflected rail level and associated accelerations and forces.

Measurements have demonstrated that the sleeper support stiffness may vary significantly from one sleeper to another, even over short lengths of track with nominally similar support conditions (e.g. Oscarsson, 2002; Bowness et al., 2007; Le Pen et al., 2014, Murray et al., 2014). Increased variability in the sleeper support stiffness from one sleeper to another along the track leads to greater variability in increments of dynamic load, which generally increases in magnitude with train speed. Variability in sleeper support stiffness is considered to cause accelerated track degradation (e.g. Hunt, 2000, Sussman et al., 2001). This is most obvious on transitions between soft and hard supports, such as the approaches/exits from bridges (e.g. Coelho et al., 2011; Paixao et al., 2013; Varandas et al., 2014; Milne et al., 2014).

Analyses of track/train interactions may be carried out using commercially available vehicle dynamics software packages (e.g. Nucars, Li et al., 1999; Adams Rail, MSC software, 2015; Vampire, DeltaRail, 2015) that characterise the track support using simple springs beneath each rail. Simulations in which components of track system stiffness vary along the track length (e.g. Bezin et al., 2009) demonstrate that significant additional dynamic loads occur in such conditions. However, despite the important influence of variations in stiffness on track performance, measurements of the system support modulus are rare.

The system modulus affects the extent to which the wheel load is spread along the length of the track. A lower system modulus gives a broader deflection bowl, reducing the contact 
stresses between the sleeper and the ballast and hence throughout the substructure, albeit at the expense of increased rail bending. Stiffer support is widely held to be associated with a reduced rate of track geometry deteroration.

Evaluating the support stiffness as trains pass usually requires:

1. Measurements of track accelerations, velocities or displacements

2. A measurement or an estimate of the axle load(s)

3. A model of track behaviour, such as the beam on an elastic foundation.

In-service track movements may be measured using geophones, accelerometers, optical methods such as the analysis of images from high speed filming (Bowness et al., 2007), Linear Variable Differential Transformers (LVDTs) or multi-depth deflectometers (MDDs; Gräbe \& Shaw, 2010). Practical considerations will determine whether a particular method of measuring track acceleration, velocity or displacement can be used at a given site (e.g. optical methods require a line of sight, and LVDTs and MDDs need a convenient fixed datum or anchor point). Also, the data obtained may need to be processed, cleaned and / or filtered (see e.g. Bowness et al., 2007; Lamas-Lopez et al., 2014; Paixão et al., 2014).

The axle load of a moving train at a given location (even from one sleeper to the next) differs from the published static axle load owing, for example, to curving forces, dynamic vehicle/track interaction, and live loading (passengers/cargo). Vehicle dynamics software such as Nucars or Vampire can be used to estimate dynamic wheel loads (see e.g. Priest et al., 2013), but such simulations require knowledge of the vehicle suspension characteristics and in service track geometry data and hence are not always practical. In principle, loads can be measured at the point of application for example using strain gauges fixed to the rail. However, such measurements must be calibrated against known applied loads (see e.g. Mishra et al., 2014, Paixão et al., 2014), which may not be easy to achieve. Also the load must be determined at each track measurement location.

Given measurements of track movements and an estimate of the load, a number of theoretical procedures based on the beam on an elastic foundation model have been proposed for determining an equivalent system modulus $\left(\mathrm{MN} / \mathrm{m}^{2}\right)$ (e.g. Kerr, 2000). This may be multiplied by the sleeper spacing to give an equivalent spring stiffness per sleeper $(\mathrm{MN} / \mathrm{m})$. A new method based on frequency analysis of the track movements, which removes the need to know the axle loads, will now be developed.

\section{Theory}

\section{Beam on elastic foundation}

The static theory has been applied to railways for many decades (e.g. Timoshenko, 1927; Raymond, 1985; Priest et al., 2013). The equations can be extended to accommodate moving load cases, as summarised below. 
Neglecting inertial or viscous effects, the governing equation for an infinite Euler-Bernoulli beam on a uniform elastic foundation subjected to a series of moving loads (Figure 1) can be shown to be (Frýba, 1972):

$E I \frac{\partial^{4} w(x, t)}{\partial x^{4}}+k w(x, t)=p(x, t)$

where:

$w(x, t)$ is vertical displacement $(\mathrm{m})$

$k$ is the support modulus $\left(\mathrm{MN} / \mathrm{m}^{2}\right)$; this is the same as the system support modulus

$E l$ is the bending stiffness of the rail $\left(\mathrm{MNm}^{2}\right)$

$p(x, t)$ represents the distributed loading on the beam.

For a single unit point load at $x=v t$, the solution to Equation 1 at an arbitrary point $x=0$ is (Frýba, 1972):

$w(t)=s(t)=\frac{1}{2 k L} e^{-\frac{v|t|}{L}}\left(\cos \left(\frac{v|t|}{L}\right)+\sin \left(\frac{v|t|}{L}\right)\right)$

where $L=\sqrt[4]{\frac{4 E I}{k}}$ is a characteristic length. This will be called the shape function; it is characteristic of the track and depends on both the rail bending stiffness and the support modulus.

For a train, $p(x, t)$ represents a series of $n$ loads $F_{n}$ at distances $d_{n}$ from the front of the train, each moving with velocity $v$

$p(x, t)=\sum_{n=1}^{N} F_{n}\left(\delta\left(x-d_{n}-v t\right)\right)$

This is a load function that is a property of the train. Combining Equations 2 and 3 the solution for the rail displacement $w(t)$ at $x=0$ takes the form:

$w(t)=\sum_{n=1}^{N} \frac{F_{n}}{2 k L} e^{-\frac{\left|v t-d_{n}\right|}{L}}\left(\cos \left(\frac{\left|v t-d_{n}\right|}{L}\right)+\sin \left(\frac{\left|v t-d_{n}\right|}{L}\right)\right)$

The solutions for velocity and acceleration can be obtained by successive differentiation of Equation 4 with respect to time.

\section{Fourier transforms}

Fourier transforms are used to evaluate the frequency content of the track movement. For the shape function $s(t)$, the Fourier transform is:

$S(\omega)=\frac{1}{2 k L} \int_{-\infty}^{\infty} e^{-\frac{v|t|}{L}}\left(\cos \left(\frac{v|t|}{L}\right)+\sin \left(\frac{v|t|}{L}\right)\right) e^{-i \omega t} d t=\frac{4 v^{3}}{4 k v^{4}+k L^{4} \omega^{4}}$ 
where $\omega$ is the circular frequency $(\omega=2 \pi f)$. The Fourier transform of the load function $p(x, t)$ is

$P(\omega)=\sum_{n=1}^{N} \int_{-\infty}^{\infty} F_{n} \delta\left(t-\frac{d_{n}}{v}\right) e^{-i \omega t} d t=\sum_{n=1}^{N} F_{n} e^{-\frac{i \omega d_{n}}{v}}$

According to Equation $4, w(t)$ can be expressed as the convolution (denoted by the symbol $*$ ) of the load function $p(x, t)$ and the shape function $s(t)$ :

$w(t)=s(t) * p(x, t)$

which after taking Fourier transforms corresponds to a product in the frequency domain:

$W(\omega)=S(\omega) P(\omega)$

where $W$ is the Fourier transform of $w$. Combining Equations 5 and 6

$W(\omega)=\frac{4 v^{3}}{4 k v^{4}+k L^{4} \omega^{4}} \sum_{n=1}^{N} F_{n} e^{-\frac{i \omega d_{n}}{v}}$

The velocity and acceleration spectra may be determined by multiplying Equation 9 by i $\omega$ and $-\omega^{2}$ respectively.

\section{An example calculation}

An example calculation, using simulated data, will now be used to illustrate the application of the BOEF model and the use of frequency analysis. The train selected is an 11 car class 390 Pendolino train (Table 1). This train was selected because it is in regular use in Europe, has a periodic axle spacing, and has a relatively large number of cars.

Using the input data from Table 1, displacement traces calculated using Equation 4 for some of the middle cars are shown in Figure 2. Results are shown for three different values of system modulus (10, 20 and $40 \mathrm{MPa}$ for a single rail) and typical rail properties (CEN $60 \mathrm{E1}$ ). The relative wheel locations are also indicated. The calculation has been carried out for a train speed of $23.9 \mathrm{~m} / \mathrm{s}$, chosen for convenience to give a car passing frequency of $1 \mathrm{~Hz}$.

Figure 2 shows that the deflections are greatest immediately beneath the wheels, and increase as the system modulus is reduced. Figures $3 a$ and $b$ show detailed results for low and high system support modulus respectively as two adjacent bogies pass. At the lower system modulus (Figure 3a), individual axles appear as minor undulations on the bogie passing deflection bowl, while between adjacent bogies on adjacent cars the rail does not return to its original level. At the higher system modulus (3b), individual axles are more distinct, while between each bogie the rail returns almost to its original level.

The frequency domain forms of the displacement shape and load functions (Equations 5 and 6 ) are illustrated in Figure 4. Figure 4a shows that displacement shape function at frequencies between $0 \mathrm{~Hz}$ and $8 \mathrm{~Hz}$ changes significantly as the system modulus increases between 10 and $40 \mathrm{MN} / \mathrm{m}^{2}$. Figure $4 \mathrm{~b}$ shows the load function plotted using a unit wheel 
load $F$ in Equation 6. This is independent of the system modulus but is a function of the train geometry.

In Figure 4b, as discussed by Ju et al. (2009), strong peaks occur at the car passing frequency ( $1 \mathrm{~Hz}$ in this case) and at most multiples thereof. The relative magnitudes at these frequencies are governed by the axle spacing of the train. In this particular case the second and fifth harmonics are weak whereas the third, seventh and tenth are strong. Although the main peaks are harmonics of the vehicle passing frequency, a feature of Figure $4 \mathrm{~b}$ is the presence of subsidiary peaks between successive harmonics; in the present case with 11 cars there are 10 subsidiary peaks between each pair of harmonics.

Multiplication of the shape function, Figure $4 a$, by the frequency domain form of the train load function in Figure $4 \mathrm{~b}$ gives the frequency response for the entire train. Figure $5 \mathrm{a}$ shows the magnitude of the Fourier transform found using Equation 9 for the displacement, and Figure $5 b$ the corresponding velocity spectrum.

Comparison of Figures $4 \mathrm{~b}$ and $5 \mathrm{a}$ for displacement amplitudes shows that multiplication by the shape function (Figure 4a) has significantly reduced the relative magnitudes at frequencies greater than $12 \mathrm{~Hz}$ and there are strong peaks at 1, 2, 3 and $7 \mathrm{~Hz}$. The fact that these peaks in the track displacement spectra all occur at relatively low frequencies and correspond to multiples of the car passing frequency agrees with the theoretical and field work of others (e.g. Bian et al., 2015, Ju, 2009, Priest et al., 2013). The velocity spectrum contains more higher frequency components owing to the multiplication by $\omega$. In each case, however, the peaks at $3 \mathrm{~Hz}$ and $7 \mathrm{~Hz}$ stand out as dominant harmonics of the vehicle passing frequency. Although these observations are for a specific train type, most trains have similar axle interval dimensions such that the $3^{\text {rd }}$ and $7^{\text {th }}$ harmonics for most trains would still be expected to be dominant.

For a given train speed $v$, the vehicle passing frequency is given by $f_{1}=v / d_{c}$ where $d_{c}$ is the car length. As the train speed is varied, the frequency axis in both Figures $4 \mathrm{a}$ and $4 \mathrm{~b}$ will shift in proportion. It is therefore convenient to normalise the frequency by $f_{1}$ in both cases and in the combined plots in Figure 5. The magnitude of $W$ also depends on train speed but the relative magnitude of the various peaks is independent of train speed. This suggests the use of the ratio of the amplitudes at two selected harmonic frequencies to determine the track system support modulus, as explained in the next section.

\section{Developing a relationship to obtain track stiffness}

Typically, trains have a repeating structure from successive cars. In Equations 3 and 6, any periodicity in the train layout is implicit. Ju et al. (2009) demonstrated that, if the train is explicitly periodic (i.e. each car has the same axle spacings, coupling distance and axle loads $F)$ then as the number of cars increases, the dominant frequencies of the train loading function tend towards the car passing frequency and its harmonics (as observed in the above example). These are given by $\omega=2 \pi n f_{1}$ for integer values of $n$, where $f_{1}=v / d_{c}$ for a vehicle length $d_{c}$. 
Taking any two harmonic frequencies $f_{p}=p f_{1}$ and $f_{q}=q f_{1}$, where $p$ and $q$ are integers substitution into Equation 9 gives two equations. Dividing one of these by the other, substituting for $L^{4}$ and simplifying, the ratio of amplitudes at the selected harmonic frequencies is:

$\frac{W(n=p)}{W(n=q)}=\frac{d_{c}{ }^{4} k+16 E I q^{4} \pi^{4}}{d_{c}{ }^{4} k+16 E I p^{4} \pi^{4}} \times \frac{\sum_{n=1}^{N} e^{-\frac{i 2 \pi p d_{n}}{d_{c}}}}{\sum_{n=1}^{N} e^{-\frac{i 2 \pi q d_{n}}{d_{c}}}}$

Conveniently, the axle loads $F$ have been eliminated. The influence of speed has also been eliminated by using harmonic multiples of the vehicle passing frequency. The second term in Equation 10 is a function only of the train geometry and can be evaluated for each type of train on a particular line. Apart from the vehicle length, $d_{c}$, the first term is a function of the track properties alone. For rails of a given bending stiffness $(E I)$, the ratio can be evaluated for different values of the system support modulus $(k)$ to derive calibration curves for each train type. The ratio of the amplitudes at the two harmonic frequencies can be measured during a train passage and the track system support modulus obtained from the appropriate calibration curve.

By applying the derivative rule, similar relationships can be developed for ratios of velocity and acceleration at chosen frequencies. These ratios are related by

$\frac{W(n=p)}{W(n=q)}=\frac{V(n=p) q}{V(n=q) p}=\frac{A(n=p) q^{2}}{A(n=q) p^{2}}$

The harmonics $p$ and $q$, should correspond to dominant peaks in the spectrum. In the example presented the $3^{\text {rd }}$ and $7^{\text {th }}$ harmonics were chosen but for other train types different harmonics may be just as or more dominant.

\section{Application to field data}

For the methods described to be appropriate for interpretation of field measurements, sites should be selected on the basis of certain minimum criteria. These are principally that (1) the track should be reasonably well-performing (i.e., no voided sleepers and no excessive variation in support stiffness from one sleeper to another) and (2) the load should remain reasonably consistent between axles on the same train. These conditions may be met by selecting well-maintained sites traversed regularly by periodic trains.

At distance from the track vibration due to long wave length rail irregularities may have peaks at the same frequencies as the moving axle loads and may dominate the quasi-static component. However, at the rail it has a much smaller amplitude than the quasi-static component for frequencies below $20 \mathrm{~Hz}$ to $30 \mathrm{~Hz}$ (Triepaischajonsak, et al., 2011; Lombaert \& Degrande, 2009). Thus it will not affect the operation of the proposed method. 


\section{Field measurements}

Sites

Previously unpublished data from various study sites will now be used to illustrate the application of frequency analysis to estimate system modulus. The data are evaluated in their native form (velocity). It has previously been demonstrated that geophone data can be used to determine track movements reliably (see e.g. see Bowness et al., 2007). However, provided that measurements of sufficient quality are available the techniques can be applied to deflection, velocity or acceleration data from any other trackside measurement technique (e.g. high speed filming, MDD or accelerometers) to achieve the same result.

The characteristics of each field study site and the types of trains passing over them, which in each case are periodic, are summarised in Table 2 . These study sites were selected because the track is believed to be performing acceptably and they cover a range of situations that may collectively be considered as typical of plain line including curved track. Measurements at each site were taken over the course of a few days, capturing a number of train passes. Over the short duration of site measurements, track behaviour remained consistent, with similarly configured trains giving very similar data. Thus only representative trains from each location are presented, except for site 3 where a subset of multiple train data is also shown to illustrate the consistency.

Data from a weighing-in-motion system (Gotcha monitoring systems, 2011) was available for the same line as site 3. Measurements of the axle load for the class 395 (Javelin) show that the in-train variation of axle load was less than $+/-4 \%$ for $90 \%$ of all the trains passing. The variation between trains was more significant: the axle loads from the heaviest trains were up to $20 \%$ greater than for the lightest trains. These data justify both the assumption that variation between axle loads within the same train is likely to be small (i.e. our method is robust), and the need for a method that does not rely on the use of nominal axle loads to calculate track system support stiffness from measured deflections which may lead to a significant error.

Further site data are summarized in Table 3, and key train characteristics are given in Table 4.

Sites $3 \mathrm{a}$ and $3 \mathrm{~b}$ are contiguous with each other on the same section of track, but are considered as two subsites owing to the number of measurements taken (twice as many sleepers were instrumented as at other sites). Sites $4 a$ and $b$ are sections of track on the same route, separated by several hundred metres.

Analytical calibration curves relating the system modulus to the amplitude ratio of the $7^{\text {th }}$ to the $3^{\text {rd }}$ harmonics of the track velocity can be developed using Equation 10 for the number of cars or axles present. However, a single calibration curve for a given train type, regardless of actual number of cars present, will normally be acceptable because the ratio of $3^{\text {rd }}$ to $7^{\text {th }}$ harmonics converges to within $2 \%$ provided that at least 4 cars are present. Thus the 
calibration curves shown in Figure 6 for an infinite number of cars can be used provided the measured trains have at least 4 cars.

The curves in Figure 6 show a show a strong correlation between amplitude and system support modulus because suitable dominant harmonic frequencies were selected. An inappropriate choice would result in flatter calibration lines and greater uncertainty in determining the system support modulus.

\section{Instrumentation}

A typical arrangement of geophones is shown in Figure 7. Generally, up to 28 sensors (representing the capacity of the two data loggers used) are fixed to brackets mounted on the sleeper ends of adjacent or alternate sleepers. These are installed under a safe system of work and then left in place to take measurements over a period of at least 20 seconds during each train passage. Data logging is at $500 \mathrm{~Hz}$, triggered automatically by an approaching train. Most trains travelling at line speed will pass the sensors in less than 10 seconds. Logging at $500 \mathrm{~Hz}$ is more than sufficient for the present analysis of frequencies up to a few tens of $\mathrm{Hz}$.

Signal processing of the recorded geophone data followed established practice including anti-aliasing to eliminate spurious frequency content. Further information on signal processing techniques is available in, for example, Santamarina \& Fratt, (2005) and Shin \& Hammond, (2008).

Checks were also carried out to ensure that the signal-to-noise ratio was sufficient for this application. In the frequency range up to $30 \mathrm{~Hz}$ the signal-to-noise ratio was more than 30 $\mathrm{dB}$, rising to more than $50 \mathrm{~dB}$ at the spectral peaks associated with the passing axles. Above $30 \mathrm{~Hz}$ the signal-to-noise ratio was still more than $20 \mathrm{~dB}$.

\section{Site data}

Deflection data from an individual sleeper for four train types at three of the four sites are presented in Figure 8. Deflections have been determined by integrating the velocity data obtained from the geophone, following the use of Butterworth band-pass filtering appropriate to the train passing speed and the geophones used; typically the lower cut-off frequency was $1 \mathrm{~Hz}$ and the upper cut-off frequency was $30 \mathrm{~Hz}$, ensuring that the frequency range analysed was unaffected by the filters. Further details of the filtering methods used are given by Le Pen et al. (2014).

Figure 8 focuses on data from only some of the middle cars, and the $y$-axis has been adjusted so that the zero position corresponds to the estimated at rest (unloaded) sleeper level. The deflection trace follows closely the form of deflection expected from the BOEF model (Figure 3). Figure 8a is annotated to show what is meant by the term "bogie deflection" (used in later calculations).

To evaluate the frequency spectra, the numerical discrete Fourrier Transform (DFT) was applied to the unfiltered measured data. When using the DFT, data become smeared about the expected frequency (Oppenheim and Schafer, 1975) and this may become significant if 
the bandwidth, i.e. the gap between adjacent frequencies (1/signal duration) evaluated is too large. It has been verified that a suitable bandwidth giving good agreement with the analytical solution is obtained for data recorded over a duration of at least 20 seconds. This is the case for all data presented in this paper. Figure 9 shows relative amplitudes of velocity spectra, with frequencies normalised to the car passing harmonics for the corresponding train from Figure 8.

In Figure 9 the $3^{\text {rd }}$ and $7^{\text {th }}$ harmonics are highlighted by arrows and the order of the harmonic can simply be read from the normalised frequency axis. As they are amongst the highest peaks for each graph, the $3^{\text {rd }}$ and $7^{\text {th }}$ harmonics can reasonably be considered to be dominant harmonics. Due to the particular axle intervals of some of these trains the $6^{\text {th }}$ harmonic is also dominant and it too could be used to determine a relationship with system support stiffness.

\section{Interpretation using frequency evaluation}

Table 5 shows the harmonic amplitude ratios obtained from the DFT of the measured data, which were used to determine the system moduli listed in Table 6 using the amplitude ratio relationships in Figure 6. Provided that the railpad and trackbed behave linearly over the range of movements in question, the amplitude ratios are the same for velocities measured on the sleeper as on the rail; thus the frequency evaluation method provides the system support modulus directly.

\section{Direct interpretation of site data}

\section{Estimate of system support moduli from sleeper deflections}

The system support modulus can also be determined from the measured track deflections and an estimate of the wheel load. Characteristic middle bogie deflections for the sleepers at the field sites, calculated using appropriate filtering and integration of the geophone data, are summarised in Table 7. Although the track is considered to be performing well at all of the sites, there are some significant variations between the movements of each sleeper. This is not untypical of ballasted track.

Measured rail deflections can be used with the BOEF model and known wheel loads to determine the system support modulus $(k)$. However, the solution for $k$ cannot be obtained in closed form because $k$ appears both directly in Equation 4 and within the characteristic length $L$. Equation 4 can be solved iteratively and the theory of superposition used to account for overlapping deflection basins from nearby wheels (Kerr, 2000).

\section{Allowance for railpad stiffness}

The measurements reported in Table 7 are for sleepers during the passage of a bogie in the middle of the train. However there is further rail movement due to the compression of the railpad. Usually, track bed or sleeper movements are several times larger than the likely railpad movement; where this is the case, omitting or negelecting the railpad component of rail movement may be reasonable. However, as the trackbed support stiffness approaches the railpad stiffness, errors can become significant. To determine the system support modulus, taking the railpad component of deflection into account, the track system can be idealised as two linear springs in series, one of stiffness $k_{\text {trackbed }}$ (representing the trackbed) 
below the sleeper and the second of stiffness $k_{\text {pad }}$ (representing the rail pad) between the sleeper and the rail. The overall system support stiffness (or modulus when multiplied by the sleeper spacing), $k_{\text {system, }}$ is given by $1 / k_{\text {system }}=1 / k_{\text {pad }}+1 / k_{\text {trackbed }}$. Substitution into Equation 4 produces a relationship that can be solved iteratively to determine $k_{\text {trackbed }}$ and hence $k_{\text {system }}$ for known measured deflections provided $k_{\text {pad }}$ is known. The railpads at sites 1,2 and 4 were $10 \mathrm{~mm}$ thick studded rubber pads (Pandrol type 6650) fastened using fastclips. Testing of these pads to the now withdrawn Railtrack specification RT/CE/S/052 over a load increment of $15 \mathrm{kN}$ to $75 \mathrm{kN}$ gave an equivalent spring stiffness of $60 \mathrm{MN} / \mathrm{m}$ per pad. Data are not available for the Vossloh pads installed at site 3; but they are unlikely to be dissimilar. Using this pad stiffness, adjusted to an equivalent modulus (per metre of track) it is possible to determine the system support modulus and trackbed modulus using the measured deflections reported in Table 7.

\section{Results for system support modulus}

Table 8 shows the system support moduli found from the deflection data in Table 7 for the particular trains, rails, sleepers and pads at each site (Tables 3 and 4). The normal force per wheel has been adjusted where needed for curving speed and cant of track using the relevant equations of motion (see e.g. Priest et al., 2013). In these calculations, the height of the centre of mass of the trains was taken as $1.65 \mathrm{~m}$, measured normal to the rail head (Le Pen, 2008).

\section{Comparison of methods}

Table 9 shows average system support and trackbed moduli for all sleepers at each site, calculated using both the direct and frequency based methods.

Figure 10 compares all the results of the direct and frequency ratio methods of calculating system modulus for all individual sleepers at each site.

The average system stiffness from the direct method is $24 \mathrm{MN} / \mathrm{m}^{2}$ and the average from the frequency method is $26 \mathrm{MN} / \mathrm{m}^{2}$ (Table 9). The trackbed support stiffnesses are similarly close $\left(37 \mathrm{MN} / \mathrm{m}^{2}\right.$ and $\left.40 \mathrm{MN} / \mathrm{m}^{2}\right)$. This implies that overall the axle loading of the track was close to the static axle loads shown in Table 4. Considering the data as a whole, the dashed lines in Figure 10 indicate the results where the agreement was within $+/-10 \mathrm{MN} / \mathrm{m}^{2}$; this covers $77 \%$ of all the data. However there are some notable differences between the two methods; these may be explained by considering the characteristics of each site.

Sites with lower support stiffness such as site 4 where two sections of track are compared several hundred metres apart show a greater proportional variation between the results calculated by each method. At Site $4 \mathrm{~A}$ the frequency method gave system support moduli some $30 \%$ smaller than the direct method while at Site $4 \mathrm{~B}$ the reverse was the case. The less consistent behaviour at site 4 is thought to have been due to a greater variation between support conditions along the track, which is typical at sites where the support stiffness is generally lower. It is likely that there were more partially or fully voided sleepers present compared with track of higher support stiffness. This is consistent with the generally accepted view that lower stiffness track requires greater maintenance. Sites with stiffer and more consistent support conditions such as site 2 show the closest agreement between the 
two methods. This can be attributed to the beam on elastic foundation model being a closer representation of this site's performance. Site 3 was a truly high speed site with generally stiff support and might therefore have been expected to have shown the best agreement between the two methods. However, it was observed during the measurements that just prior to the monitored section there were several partly voided (hanging) sleepers forming a dip in the track. The excitation of the train suspension system as it traversed the dip would have resulted in much greater than usual changes in the dynamic load. This uncertainty in the actual load needed for the reliable calculation of the system support modulus for the direct metfhod has undoubtedly adversely affected the agreement.

For the site where two different train types passed over the same sleepers (site 1), the system support modulus appears greater for the heavier train (the Supervoyager), perhaps indicating that the behaviour of the system is non-linear.

To illustrate the consistency of the frequency method, data from the first 6 sleepers at Site 3 representative of 24 trains travelling between $57 \mathrm{~m} / \mathrm{s}$ and $62 \mathrm{~m} / \mathrm{s}$ passing over the site on the same day are plotted in Figure 11.

Except for the outliers on sleepers 1 and 3, which are perhaps a result of these sleepers having a particularly low system support modulus, these results are consistent.

The analysis presented is based on the assumption of uniform trackbed and railpad behaviour, with linear elasticity throughout the system. In practice, behaviour is non-linear and support properties vary along the track length. Nonetheless the frequency analysis method proposed provides a repeatable approach to measuring system support modulus without the need to know the wheel load, and offers new insights into track behaviour. For ongoing monitoring purposes, changes in the amplitude ratios of selected harmonic frequencies would provide evidence of changing system support modulus and developing trackbed faults.

\section{Conclusions}

1. A new method has been presented which enables the track system support modulus to be determined from trackside measurements without the need to measure the wheel load. The approach uses frequency analysis of displacement, velocity or acceleration measured on the sleeper (or rail) with the results interpreted using a model of a beam on an elastic foundation.

2. The method is applicable to field data obtained using a variety of techniques, including geophones, accelerometers, MDDs, LVDTs and digital correlation of images obtained by high speed filming.

3. Support moduli obtained using the frequency-based approach are on average close to those determined directly from the estimated quasi-static wheel load (which accounts for the vehicle weight and curving at a cant deficiency) and the measured deflection, adjusted 
for load spreading along the track and the compression of the railpad. Both absolute and percentage discrepancies reduce significantly with increasing system support stiffness. Significant discrepancies at one site were probably as a result of vehicle excitations causing a greater than usual variability in the dynamic wheel loads.

\section{ACKNOWLEDGEMENTS}

The authors are grateful for the financial support of the Engineering and Physical Sciences Research Council (EPSRC) through the Programme grant TRACK21 (EP/H044949/1), and for the financial support of Network Rail through the University Research Partnership in Future Infrastructure Systems. This work would also not have been possible without the kind assistance and advice given by a number of current and past Network Rail and HS1 employees including Andrew Cornish, Frank Evans, Paul Parcell, Robert Holbrow, Mike Edwards, Mick Hayward and Simon Morley. Steve Cox of Pandrol provided information on the railpads. Andrew Hudson, Geoff Watson and Taufan Abadi of the University of Southampton assisted with site work. All data supporting this study are openly available from the University of Southampton repository at 10.5258/SOTON/391563

\section{REFERENCES}

Abadi, T. C. 2015. Effect of sleeper and ballast interventions on rail track performance. Thesis of Doctor of Philosophy, Faculty of Engineering and the Environment, University of Southampton, Southampton, U.K.

Bowness, D., Lock, A. C., Powrie, W., Priest, J. A. \& Richards, D. J. 2007. Monitoring the dynamic displacements of railway track. Proceedings of the Institution of Mechanical Engineers, Part F (Journal of Rail and Rapid Transit), 221, 13-22.

Bian, X., Jiang, H., Chang, C., Hu, J. \& Chen, Y. 2015. Track and ground vibrations generated by high-speed train running on ballastless railway with excitation of vertical track irregularities. Soil Dynamics and Earthquake Engineering, 76, 29-43.

Bezin, Y., Iwnicki, S. D., Cavalletti, M., De Vries, E., Shahzad, F. \& Evans, G. 2009. An investigation of sleeper voids using a flexible track model integrated with railway multi-body dynamics. Proceedings of the Institution of Mechanical Engineers, Part F: Journal of Rail and Rapid Transit, 223, 597-607.

Coelho, B., Hölscher, P., Priest, J., Powrie, W. \& Barends, F. 2011. An assessment of transition zone performance. Proceedings of the IMechE Part F, Journal of Rail and Rapid Transit, 225, 129.

Grassie, S.L. Cox, S.J. 1984: The dynamic response of railway track with flexible sleepers to high frequency vertical excitation, Proc. Instn Mech. Engrs Vol 198D No7 117-124, .

DeltaRail 2015. http://www.vampire-dynamics.com/. DeltaRail Group Ltd.

Esveld, C. 2001. Modern Railway Track, Zaltbommel, MRT Productions.

Frýba, L. 1972. Vibration of solids and structures under moving loads, Groningen, The Netherlands, Noordhoff.

Gotcha Montioring Systems (2011) A flexible monitoring platform for advanced asset management of rolling stock and infrastructure: system description. Lloyd's Register Rail Europe B.V. [Online]: http://www.gotchamonitoringsystems.com/ 
Gräbe, P. J. \& Shaw, F. J. 2010. Design Life Prediction of a Heavy Haul Track Foundation. Proceedings of the Institution of Mechanical Engineers, Part F: Journal of Rail and Rapid Transit, 224, 337-344.

Hunt, G. A. 2000. EUROBALT optimises ballasted track. Railway Gazette International, 156, 813.

Ju, S.-H., Lin, H.-T. \& Huang, J.-Y. 2009. Dominant frequencies of train-induced vibrations. Journal of Sound and Vibration, 319, 247-259.

Kerr, A. D. 2000. On the determination of the rail support modulus k. International Journal of Solids and Structures, 37, 4335-4351.

Lamas-Lopez, F., Alves-Fernandes, V., Cui, Y. J., Costa D'aguiar, S., Calon, N., Canou, J., Dupla, J. C., Tang, A. M. \& Robinet, A. 2014. Assessment of the double integration method using accelerometers data for conventional railway platforms. In Proc: The Second International Conference on Railway Technology : Research, Development and Maintenance, 8-11 April 2014. , Ajaccio, France.

Le Pen, L., Watson, G. V. R., Powrie, W., Yeo, G., Weston, P. \& Roberts, C. 2014. The Behaviour Of Railway Level Crossings: Insights Through Field Monitoring. Transportation Geotechnics, Special issue: Rail Geomechanics.

Le Pen, L. 2008. TRACK BEHAVIOUR: THE IMPORTANCE OF THE SLEEPER TO BALLAST INTERFACE, Thesis. Department of Civil and Environmental Engineering, University of Southampton.

Li, D., Elkins, J. A., Otter, D. E. \& Wilson, N. G. 1999. Vehicle/track dynamic models for wheel/rail forces and track response. Heavy Vehicle Systems, 6, 345-359.

Lombaert, G., Degrande, G. 2009. Ground-borne vibration due to static and dynamic axle loads of Intercity and high-speed trains. Journal of Sound and Vibration 319, 10361066.

Murray, C. A., Take, W. A. \& Hoult, N. A. 2014. Measurement of vertical and longitudinal rail displacements using digital image correlation. Canadian Geotechnical Journal, 52, 141-155.

Mscsoftware 2015. http://web.mscsoftware.com/Products/CAE-Tools/Adams.aspx. MSC Software Corporation.

Milne, D., Le Pen, L., Powrie, W., Thompson, D. J., Watson, G. V. R., Morley, S. \& Hayward, M. 2014. The influence of structural response on ballast performance on a high speed railway, 08 - 10 Dec 2014. International Conference on High Speed Rail. Birmingham, GB.

Mishra, D., Tutumluer, E., Kazmee, H. \& Boler, H. 2014. Use of Multidepth Deflectometers and Strain Gauges to Investigate the Differential Movement at Railway Bridge Approaches. In Proc: POMBO, J., ed. The second International Conference on Railway Technology: Research, Development and Maintenance, Ajaccio, Corsica. Civil-Comp Press, Stirlingshire, UK, Paper 130, 2014. doi:10.4203/ccp.104.130

Oppenheim, A. V. \& Schafer, R. W. 1975. Digital signal processing, Prentice-Hall, Inc, 1975.

Oscarsson, J. 2002. Simulation of train-track interaction with stochastic track properties. Vehicle System Dynamics, 37, 449-469.

Paixao, A., Fortunato, E. \& Calcada, R. 2013. Design and construction of backfills for railway transition zones. Journal of Rail and Rapid Transit, Online 28 August. 
Paixão, A., Alves Ribeiro, C., Pinto, N., Fortunato, E. \& Calçada, R. 2014. On the use of under sleeper pads in transition zones at railway underpasses: experimental field testing. Structure and Infrastructure Engineering, 11, 112-128.

Priest, J. A. and Powrie, W. (2009) Determination of dynamic track modulus from measurement of track velocity during train passage. Journal of Geotechnical and Geoenvironmental Engineering, 135, (11), 1732-1740. (doi:10.1061/(ASCE)GT.19435606.0000130).

Priest, J., Powrie, W., Le Pen, L., Mak, P. \& Burstow, M. 2013. The effect of enhanced curving forces on the behaviour of canted ballasted track. Journal of Rail and Rapid Transit, 227.

Priest, J., Powrie, W., Le Pen, L., Mak, P. \& Burstow, M. 2013. The effect of enhanced curving forces on the behaviour of canted ballasted track. Journal of Rail and Rapid Transit, vol 227 no. 3, pages 229 to 244.

Rail Safety and Standards Board. 2005. Review of the effect of track stiffness on track performance [Online]. Available:

http://www.rssb.co.uk/SiteCollectionDocuments/pdf/reports/Research/T372 Review of the Effect of Track Stiffness on Track Performance.pdf [Accessed 2015].

Raymond, G. P. 1985. Analysis of Track Support and Determination of Track Modulus. Transportation Research Record, 1022, 80-90.

Santamarina, J. C. \& Fratta, D. 2005. Discrete Signals and Inverse Problems: An Introduction for Engineers and Scientists, John Wiley and Sons Ltd, The Atrium, Southern Gate, Chichester, West Sussex, PO19 8SQ, England

Shenton, M. J. 1984. Ballast deformation and track deterioration. In Proc: Track Technology. Proceedings of a conference organized by the Institution of Civil Engineers, University of Nottingham, UK. Pages 253 to 265.

Shin, K. \& Hammond, J. 2008. Fundamentals of Signal Processing for Sound and Vibration Engineers, John Wiley and Sons Ltd, The Atrium, Southern Gate, Chichester, West Sussex, PO19 8SQ, England.

Sussman, T. R., Ebersohn, W. \& Selig, E. T. 2001. Fundamental Nonlinear Track LoadDeflection Behaviour for Condition Evaluation. Transportation Research Record, 1742, 61 to 67.Timoshenko, S. 1927. Proceedings Second International Congress of Applied Mechanics: Methods of Analysis of Statical and Dynamical Stresses in Rails. In Proc: Zurich. 407-418

Timoshenko, S. 1927. Proceedings Second International Congress of Applied Mechanics: Methods of Analysis of Statical and Dynamical Stresses in Rails. In Proc: Zurich. 407418,

Triepaischajonsak, N., Thompson, D.J., Jones, C.J.C., Ryue, J., Priest, J.A. 2011 Ground vibration from trains: experimental parameter characterization and validation of a numerical model. Proceedings of the Institution of Mechanical Engineers, Part F: Journal of Rail and Rapid Transit 225, 140-153.

Varandas, J. N., Hölscher, P. \& Silva, M. A. 2014. Settlement of ballasted track under traffic loading: Application to transition zones. Proceedings of the Institution of Mechanical Engineers, Part F: Journal of Rail and Rapid Transit, 228, 242-259. 
TABLES:

Table 1. Train/track data used for Pendolino simulation

\begin{tabular}{|c|c|c|c|}
\hline & Value & Units & Notes \\
\hline Wheel load $\left(\boldsymbol{F}_{\boldsymbol{n}}\right)$ & 0.063 & $\mathrm{MN}$ & $\begin{array}{c}\text { Average Pendolino wheel } \\
\text { load (Le Pen, 2008) }\end{array}$ \\
\hline Young's modulus of rail $\boldsymbol{E}$ & $2.05 \times 10^{5}$ & $\mathrm{MN} / \mathrm{m}^{2}$ & Steel \\
\hline $\begin{array}{c}\text { Second moment of area of } \\
\text { rail }(\boldsymbol{l})\end{array}$ & $3.0383 \times 10^{-5}$ & $\mathrm{~m}^{4}$ & CEN 60 E1 \\
\hline Axle locations $\left(\boldsymbol{d}_{\boldsymbol{n}}\right)$ & $0,2.7,17.0,19.7$ & $\mathrm{~m}$ & $\begin{array}{c}\text { axle spacing relative to axle } \\
1 \text { on first car }\end{array}$ \\
\hline Car length $\left(\boldsymbol{d}_{\boldsymbol{c}}\right)$ & 23.9 & $\mathrm{~m}$ & Car length when coupled \\
\hline
\end{tabular}

Table 2. Monitoring sites and trains

\begin{tabular}{|c|c|c|c|c|c|}
\hline Site & Type of line & Location & Notes & Type of train & Speed \\
\hline 1 & $\begin{array}{l}\text { Classic high } \\
\text { speed }\end{array}$ & $\begin{array}{l}\text { English } \\
\text { midlands }\end{array}$ & $\begin{array}{l}\text { Stoneblown } \\
2013\end{array}$ & $\begin{array}{l}\text { Pendolino (class 390) } \\
\text { Supervoyager (class 221) }\end{array}$ & $\begin{array}{l}125 \mathrm{mph} \\
(200 \mathrm{~km} / \mathrm{h})\end{array}$ \\
\hline 2 & Branch line & SE England & $\begin{array}{l}\text { Renewed } \\
2013\end{array}$ & Turbostar (class 171) & $\begin{array}{l}70 \mathrm{mph}(112 \\
\mathrm{km} / \mathrm{h})\end{array}$ \\
\hline $\begin{array}{l}3(a) \& \\
\text { (b) }\end{array}$ & $\begin{array}{l}\text { True high } \\
\text { speed (HS1) }\end{array}$ & SE England & $\begin{array}{l}\text { Opened } \\
2003\end{array}$ & Javelin (class 395) & $\begin{array}{l}140 \mathrm{mph} \\
(225 \mathrm{~km} / \mathrm{h})\end{array}$ \\
\hline $\begin{array}{l}4(a) \& \\
\text { (b) }\end{array}$ & Branch line & SE England & $\begin{array}{l}\text { (a) Renewed } \\
2012 \\
\text { (b) Renewed } \\
2014\end{array}$ & Electrostar (class 377) & $\begin{array}{l}75 \mathrm{mph} \\
(120 \mathrm{~km} / \mathrm{h})\end{array}$ \\
\hline
\end{tabular}

Table 3. Characteristics of sites

\begin{tabular}{|l|l|l|l|l|l|l|l|}
\hline Site & $\begin{array}{l}\text { Date of } \\
\text { measurements }\end{array}$ & $\begin{array}{l}\text { Radius of } \\
\text { track }(\mathrm{m})\end{array}$ & $\begin{array}{l}\text { Cant } \\
(\mathrm{mm})\end{array}$ & Rail type & Rail pads & Sleeper & $\begin{array}{l}\text { Sleeper } \\
\text { spacing (m) }\end{array}$ \\
\hline 1 & Aug 14 & 2777 & 72 & CEN 60 E1 & Pandrol 6650 & $\begin{array}{l}\text { Monoblock } \\
\text { (G44) }\end{array}$ & 0.65 \\
\hline 2 & May 14 & 2777 & 72 & CEN 56 E & Pandrol 6650 & $\begin{array}{l}\text { Monoblock } \\
\text { (EG47) }\end{array}$ & 0.65 \\
\hline $\begin{array}{l}\text { 3a } \\
\text { and } \\
\text { b }\end{array}$ & May 14 & $\begin{array}{l}\text { N/A } \\
\text { (Straight) }\end{array}$ & 0 & CEN 60 E1 & $\begin{array}{l}\text { Vossloh } \\
\text { ZW900 }\end{array}$ & Twin block & 0.60 \\
\hline $\begin{array}{l}4 a \\
\text { and } \\
\text { b }\end{array}$ & $\begin{array}{l}\text { Feb 13 \& Apr } \\
15\end{array}$ & $\begin{array}{l}\text { N/A } \\
\text { (Straight) }\end{array}$ & 0 & CEN 56 E & Pandrol 6650 & $\begin{array}{l}\text { Monoblock } \\
\text { (EG47) }\end{array}$ & 0.65 \\
\hline
\end{tabular}


Table 4. Train data

\begin{tabular}{|l|l|l|l|l|l|}
\hline Site & Train class & Name & $\begin{array}{l}\text { Published } \\
\text { axle weight } \\
(\text { tonnes })\end{array}$ & $\begin{array}{l}\text { Car length } \\
\left(d_{c}\right)\end{array}$ & $\begin{array}{l}\text { Axle locations } \\
\text { per car }\left(d_{n}\right)\end{array}$ \\
\hline 1 & 390 & Pendolino & 12.9 & 23.9 & $0,2.7,17,19.7$ \\
\hline 1 & 221 & Supervoyager & 14.1 & 22.9 & $0,2.6,15.9,18.5$ \\
\hline 2 & 171 & Turbostar & 11.0 & 23.6 & $0,2.6,15.8,18.4$ \\
\hline 3 & 395 & Javelin & 10.9 & 20.0 & $0,2.6,14.2,16.8$ \\
\hline 4 & 377 & Electrostar & 11.0 & 20.0 & $0,2.6,14.2,16.8$ \\
\hline
\end{tabular}

Table 5. Amplitude ratios ( $7^{\text {th }} / 3^{\text {rd }}$ harmonics) used with calibration curves in Figure 6 to determine the system support moduli in Table 6

\begin{tabular}{|l|c|c|c|c|c|c|c|c|c|c|c|}
\hline \multirow{2}{*}{ train } & \multirow{2}{*}{ site } & \multicolumn{10}{|c|}{ Amplitude ratio for sleepers: } \\
\cline { 3 - 14 } & & 1 & 2 & 3 & 4 & 5 & 6 & 7 & 8 & 9 & 10 \\
\hline 390 & 1 & 1.26 & 1.25 & 1.05 & 0.95 & 1.06 & 0.96 & 0.81 & 1.10 & & \\
\hline 221 & 1 & 1.16 & 1.16 & 0.98 & 0.76 & 0.86 & 0.94 & 0.80 & 0.88 & & \\
\hline 171 & 2 & 0.85 & 0.68 & 0.67 & 0.83 & 0.77 & 0.72 & 0.74 & 0.76 & 0.69 & \\
\hline 395 & $3 \mathrm{~A}$ & 0.91 & 2.10 & 1.20 & 1.93 & 1.93 & 1.72 & 1.62 & 1.17 & 2.02 & 2.37 \\
\hline & 3B & 1.91 & 1.72 & 1.92 & 1.63 & 1.44 & 1.83 & 0.65 & 1.90 & 1.35 & 1.61 \\
\hline 377 & 4A & 1.05 & 0.92 & 0.73 & 1.26 & 0.93 & 0.95 & 1.37 & 0.58 & 1.18 & 0.85 \\
\hline & 4B & 1.10 & 0.37 & 1.36 & 1.20 & 0.94 & 0.65 & 1.12 & 1.47 & 0.58 & 0.91 \\
\hline
\end{tabular}

Table 6. System support moduli obtained from amplitude ratios in Table 5 and calibration curves in Figure 6

\begin{tabular}{|l|c|c|c|c|c|c|c|c|c|c|c|}
\hline \multirow{2}{*}{ Train } & \multirow{2}{*}{ site } & \multicolumn{10}{|c|}{ System modulus $\left(\mathrm{MN} / \mathrm{m}^{2}\right)$ for sleepers: } \\
\cline { 3 - 14 } & & 1 & 2 & 3 & 4 & 5 & 6 & 7 & 8 & 9 & 10 \\
\hline 390 & 1 & 28 & 27 & 21 & 18 & 21 & 18 & 14 & 22 & & \\
\hline 221 & 1 & 35 & 35 & 27 & 18 & 22 & 25 & 20 & 23 & & \\
\hline 171 & 2 & 42 & 29 & 28 & 41 & 35 & 32 & 33 & 35 & 29 & \\
\hline 395 & 3 & 16 & 53 & 23 & 47 & 47 & 39 & 36 & 22 & 50 & 64 \\
\hline 395 & 3 & 46 & 39 & 47 & 37 & 22 & 43 & 9 & 46 & 28 & 36 \\
\hline 377 & 4 A & 15 & 12 & 8.4 & 19 & 12 & 13 & 22 & 5.7 & 17 & 11 \\
\hline & $4 \mathrm{~B}$ & 16 & 2.1 & 21 & 18 & 12 & 7.0 & 16 & 24 & 5.7 & 12 \\
\hline
\end{tabular}


Table 7. Measured middle bogie deflection range

\begin{tabular}{|c|c|c|c|c|c|c|c|c|c|c|c|}
\hline \multirow{2}{*}{ train } & \multirow{2}{*}{ site } & \multicolumn{8}{|c|}{ Middle bogie deflection (mm) for sleeper numbers: } \\
\cline { 3 - 14 } & & 1 & 2 & 3 & 4 & 5 & 6 & 7 & 8 & 9 & 10 \\
\hline 390 & 1 & 1.66 & 1.30 & 1.60 & 1.53 & 1.35 & 1.44 & 1.36 & 2.44 & & \\
\hline 221 & 1 & 1.71 & 1.34 & 1.51 & 1.46 & 1.36 & 1.49 & 1.42 & 2.25 & & \\
\hline 171 & 2 & 0.49 & 0.89 & 0.65 & 0.79 & 0.82 & 0.63 & 0.60 & 0.74 & 0.56 & \\
\hline 395 & $3 \mathrm{~A}$ & 1.65 & 1.55 & 1.21 & 1.54 & 0.30 & 0.51 & 0.25 & 0.26 & 0.29 & 0.64 \\
\hline 395 & 3B & 0.30 & 0.42 & 0.38 & 0.29 & 0.46 & 0.41 & 0.72 & 0.35 & 0.37 & 0.48 \\
\hline 377 & 4A & 1.69 & 2.56 & 2.21 & 1.71 & 1.64 & 2.07 & 3.24 & 2.09 & 1.93 & 2.08 \\
\hline & 4B & 0.94 & 1.31 & 0.73 & 0.71 & 1.22 & 1.23 & 0.91 & 1.26 & 2.32 & 2.33 \\
\hline
\end{tabular}

Table 8: System modulus evaluated from direct method

\begin{tabular}{|l|c|c|c|c|c|c|c|c|c|c|c|}
\hline \multirow{2}{*}{ train } & \multirow{2}{*}{ site } & \multicolumn{10}{|c|}{ System modulus $\left(\mathrm{MN} / \mathrm{m}^{2}\right)$ for sleeper numbers: } \\
\cline { 3 - 14 } & & 1 & 2 & 3 & 4 & 5 & 6 & 7 & 8 & 9 & 10 \\
\hline 390 & 1 & 16 & 20 & 16 & 17 & 19 & 18 & 19 & 11 & & \\
\hline 221 & 1 & 17 & 21 & 19 & 20 & 21 & 19 & 20 & 13 & & \\
\hline 171 & 2 & 39 & 24 & 32 & 27 & 26 & 32 & 34 & 29 & 36 & \\
\hline 395 & 3 A & 13 & 13 & 17 & 14 & 50 & 36 & 56 & 54 & 51 & 30 \\
\hline 395 & $3 \mathrm{~B}$ & 50 & 41 & 44 & 52 & 38 & 41 & 27 & 46 & 45 & 37 \\
\hline 377 & 4A & 12 & 8.2 & 9.5 & 12 & 13 & 10 & 6 & 10 & 11 & 10 \\
\hline 377 & 4B & 22 & 16 & 27 & 28 & 17 & 17 & 22 & 17 & 9.0 & 9.0 \\
\hline
\end{tabular}

Table 9: Comparison of average results for system and trackbed support moduli

\begin{tabular}{|l|l|l|l|l|l|l|l|}
\hline Site & \multirow{2}{*}{$\begin{array}{l}\text { Train } \\
\text { class }\end{array}$} & & \multicolumn{3}{l}{ Average modulus $\left(\mathrm{MN} / \mathrm{m}^{2}\right)$ calculated using: } & \multicolumn{2}{l|}{$\begin{array}{l}\text { Ratio of results } \\
\text { (frequency } \\
\text { method/direct method) }\end{array}$} \\
\hline & & System & Trackbed & System & Trackbed & system & trackbed \\
\hline 1 & 390 & 17 & 21 & 21 & 28 & 1.2 & 1.3 \\
\hline 1 & 221 & 19 & 24 & 26 & 35 & 1.4 & 1.5 \\
\hline 2 & 171 & 31 & 47 & 34 & 53 & 1.1 & 1.1 \\
\hline $3 \mathrm{~A}$ & 395 & 33 & 52 & 40 & 70 & 1.2 & 1.3 \\
\hline $3 \mathrm{~B}$ & 395 & 42 & 77 & 35 & 57 & 0.84 & 0.74 \\
\hline 4A & 377 & 10 & 12 & 13 & 16 & 1.31 & 1.4 \\
\hline 4B & 377 & 18 & 23 & 13 & 16 & 0.73 & 0.68 \\
\hline Overall & & 24 & 37 & 26 & 40 & 1.11 & 1.15 \\
\hline
\end{tabular}


FIGURES:

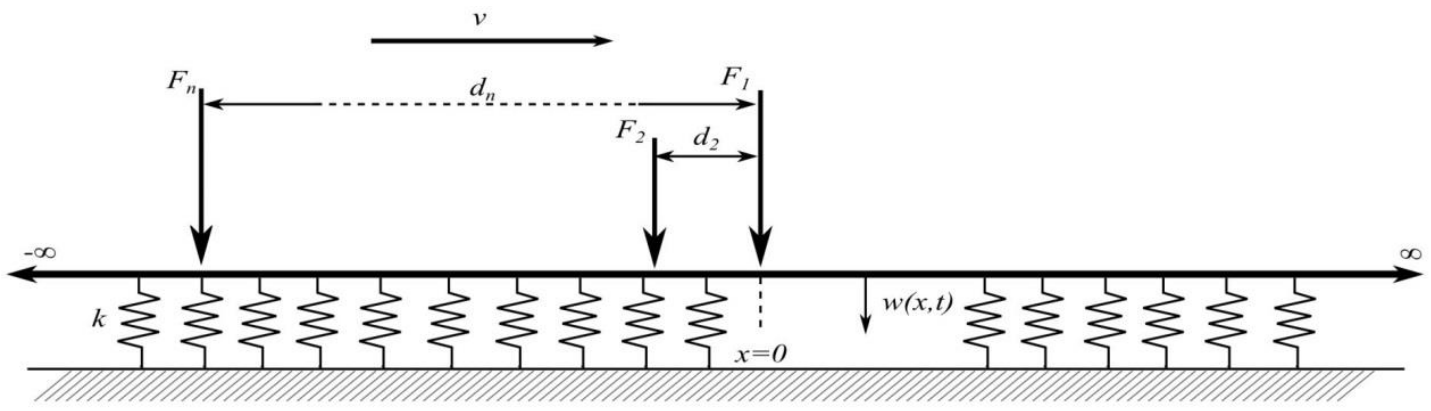

Figure 1. Infinite Beam on Elastic Foundation Quasi-Static Model

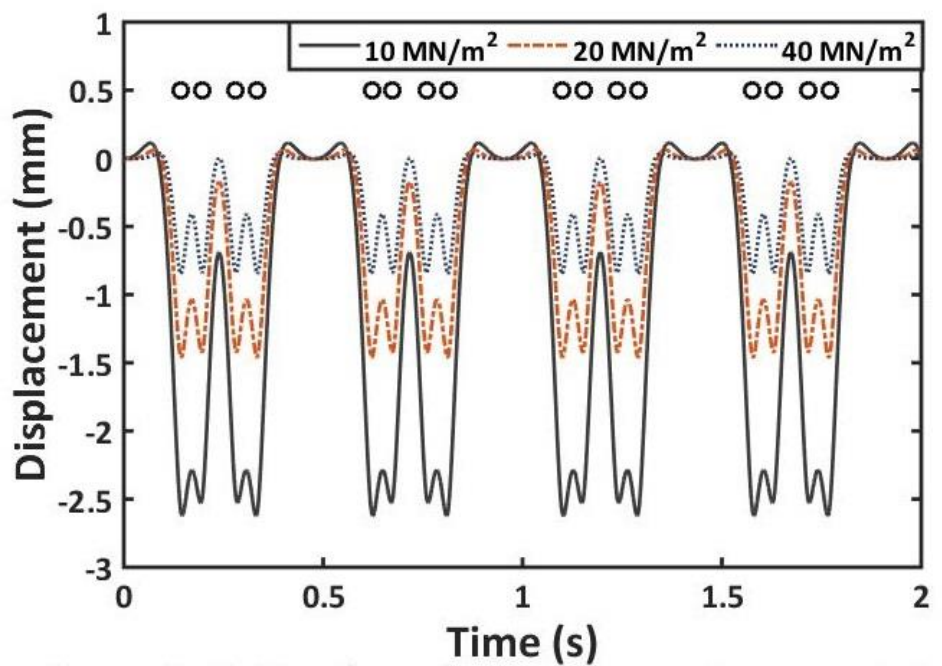

Figure 2. Deflections for varying system moduli
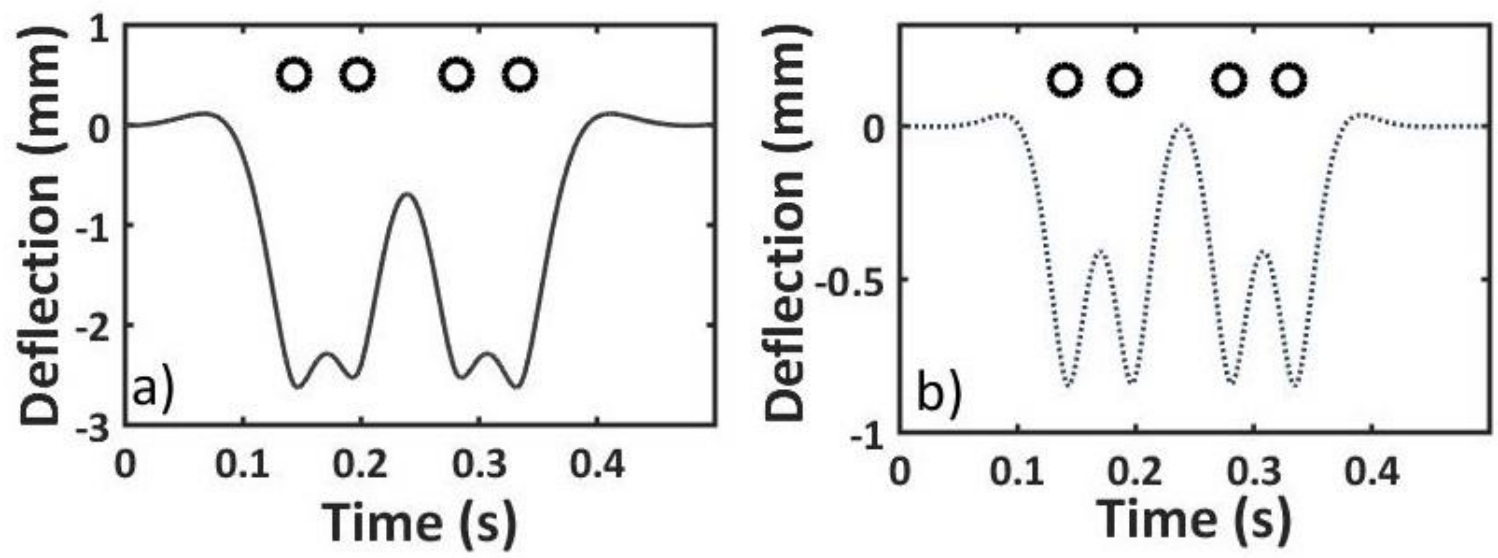

Figure 3. Deflections for (a) a soft foundation, (b) a stiff foundation. 

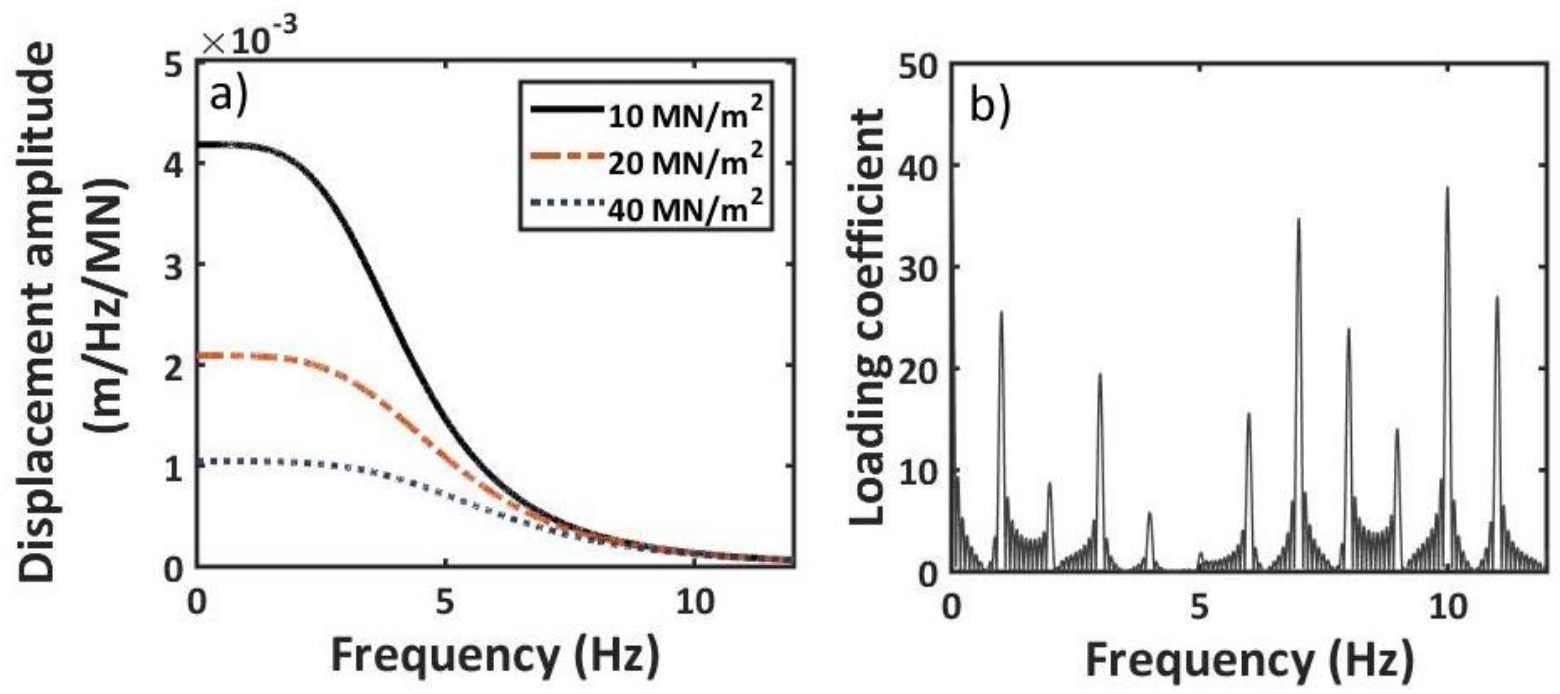

Figure 4. Fourier transforms for (a) displacement shape function for varying system modulus (b) Loading function for a Pendolino at a speed of $23.9 \mathrm{~m} / \mathrm{s}$
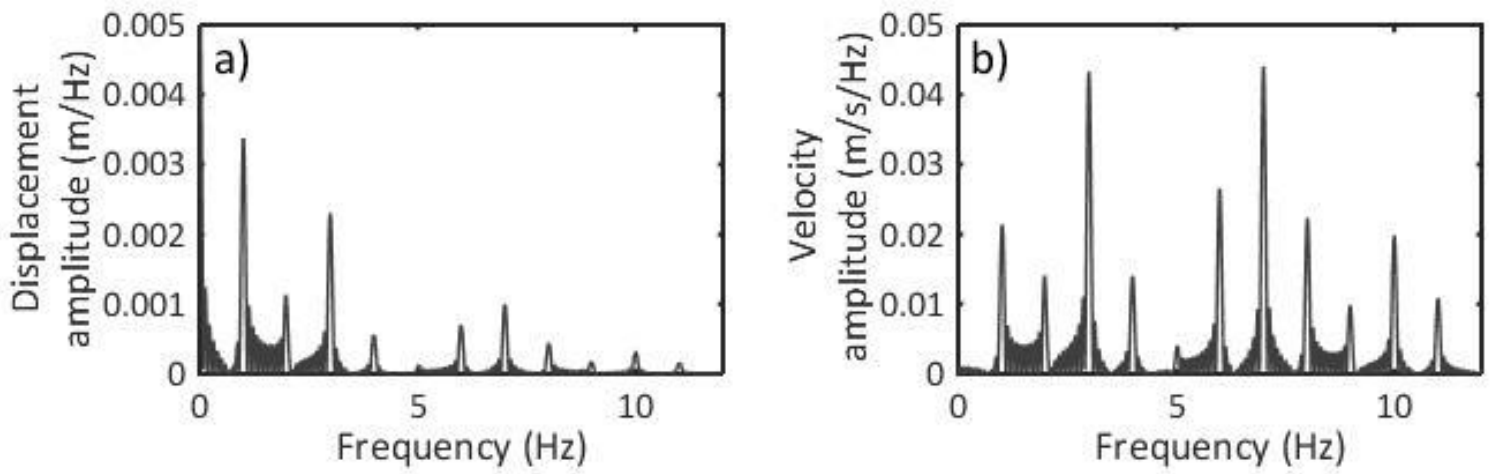

Figure 5. Example spectra for (a) displacement, (b) velocity for a Pendolino with a speed of $23.9 \mathrm{~m} / \mathrm{s}$ and system modulus of $20 \mathrm{MN} / \mathrm{m}^{2}$

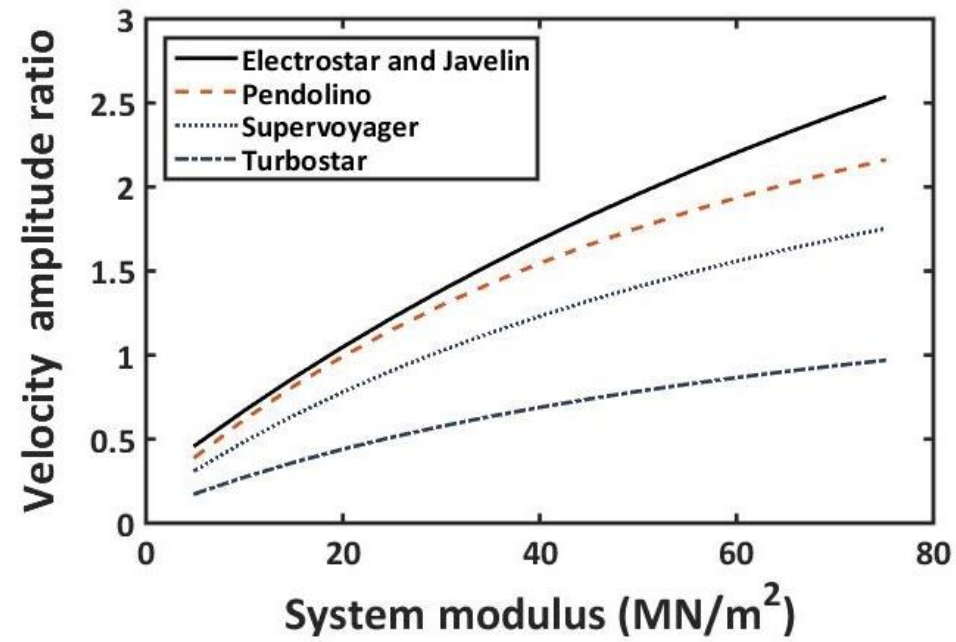

Figure 6. System modulus calibration curves for the $7^{\text {th }}: 3^{\text {rd }}$ harmonic velocity amplitude ratios for different train types 


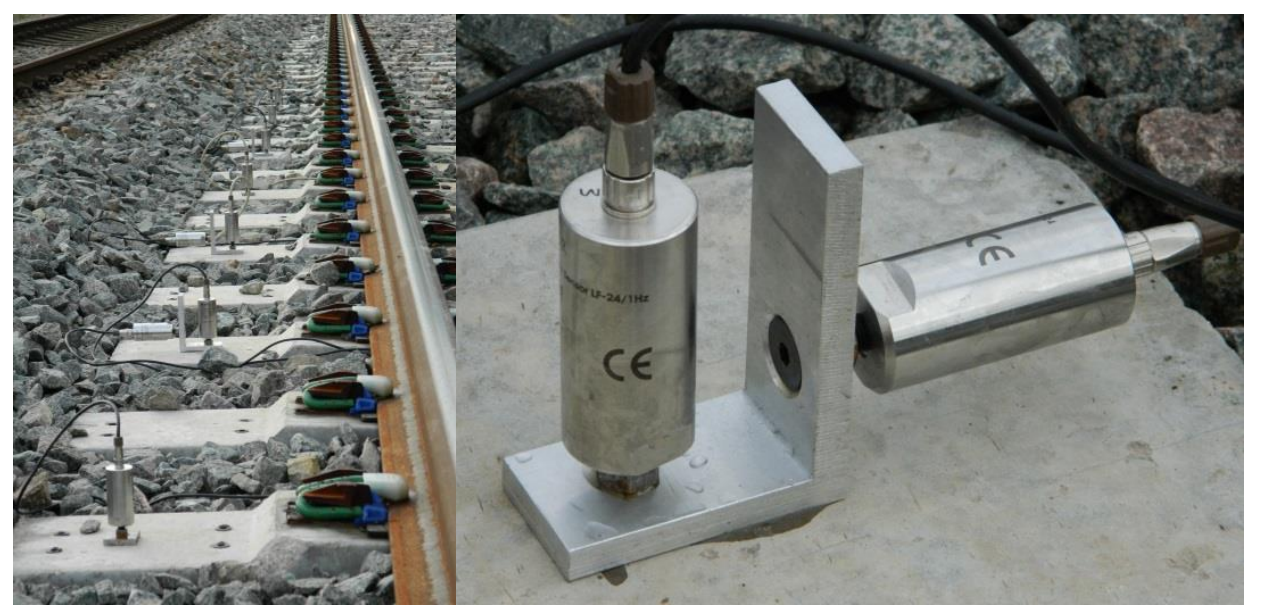

Figure 7. (a) Geophones on the sleeper ends, (b) oriented to measure vertical and lateral velocities
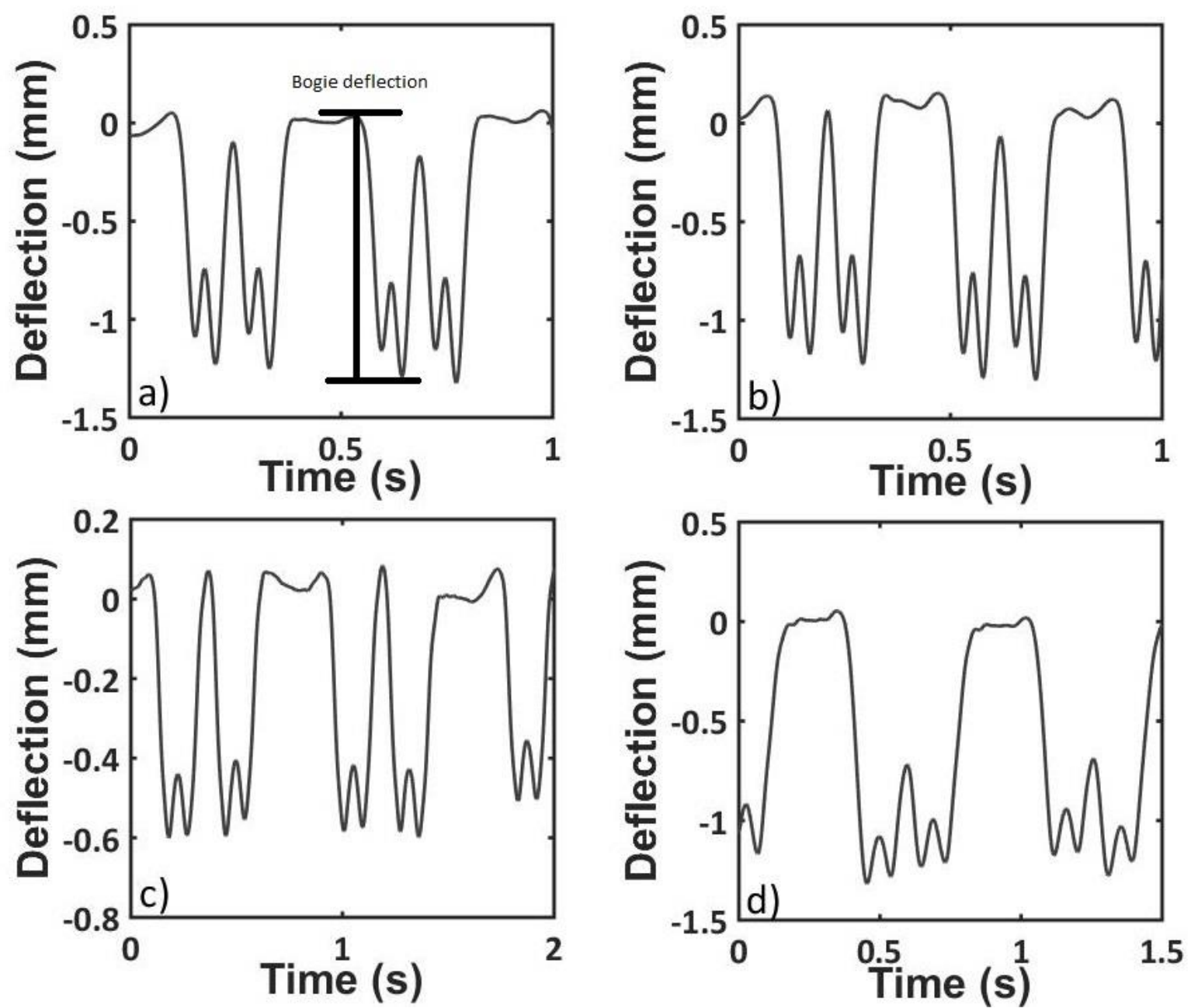

Figure 8. Measured deflection data for (a) an 11 car Pendolino at S1 (b) a 5 car Supervoyager at S1 (c) 6 car Turbostar at S2 (d) a 4 car Electrostar at S4 (deflections determined by filtering and integration of velocities from geophones) 

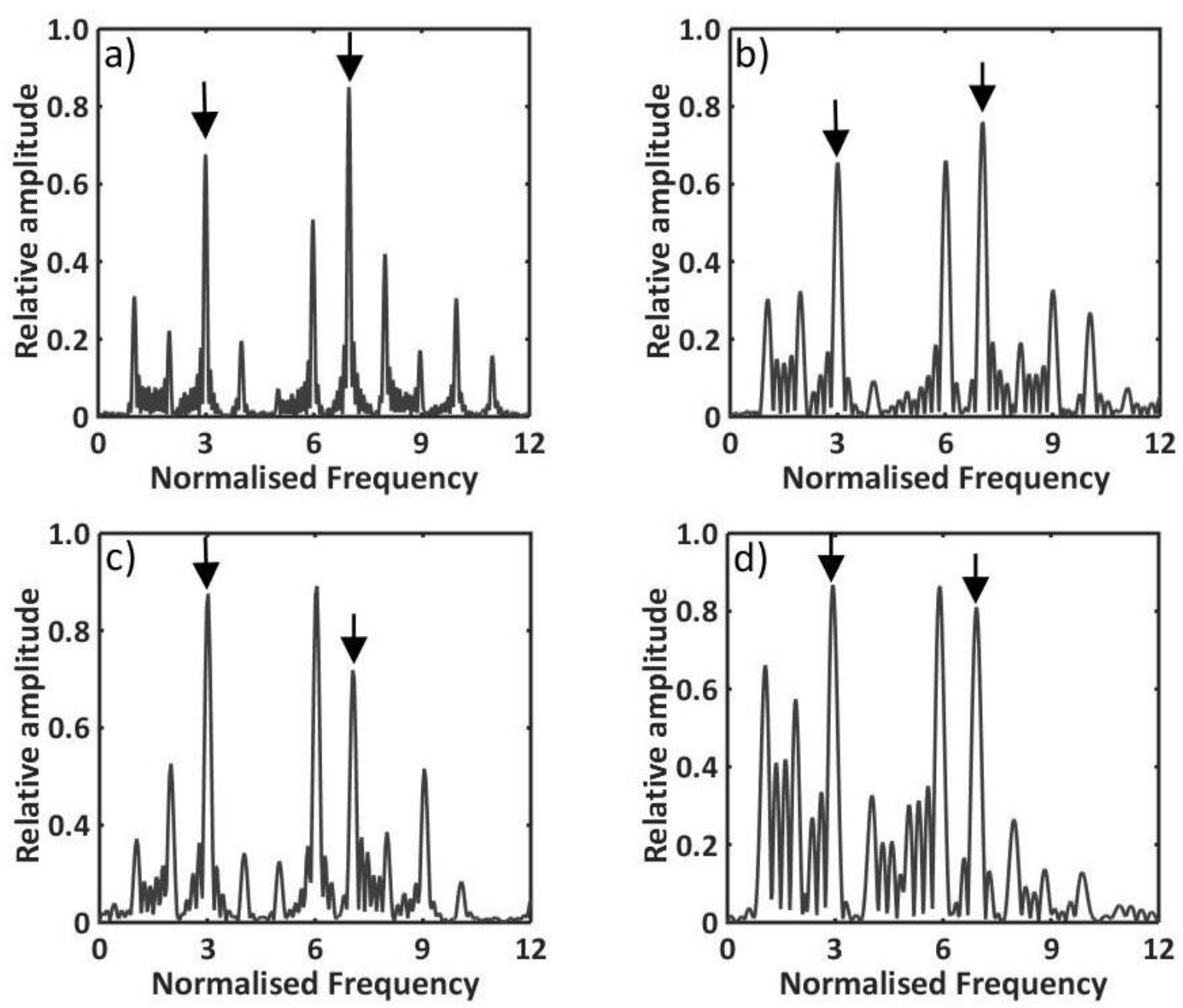

Figure 9. Numerical FFT for measured velocity data from (a) an 11 car Pendolino at S1 (b) a 5 car Supervoyager at S1 (c) 6 car Turbostar at S2 (d) a 4 car Electrostar at S4 


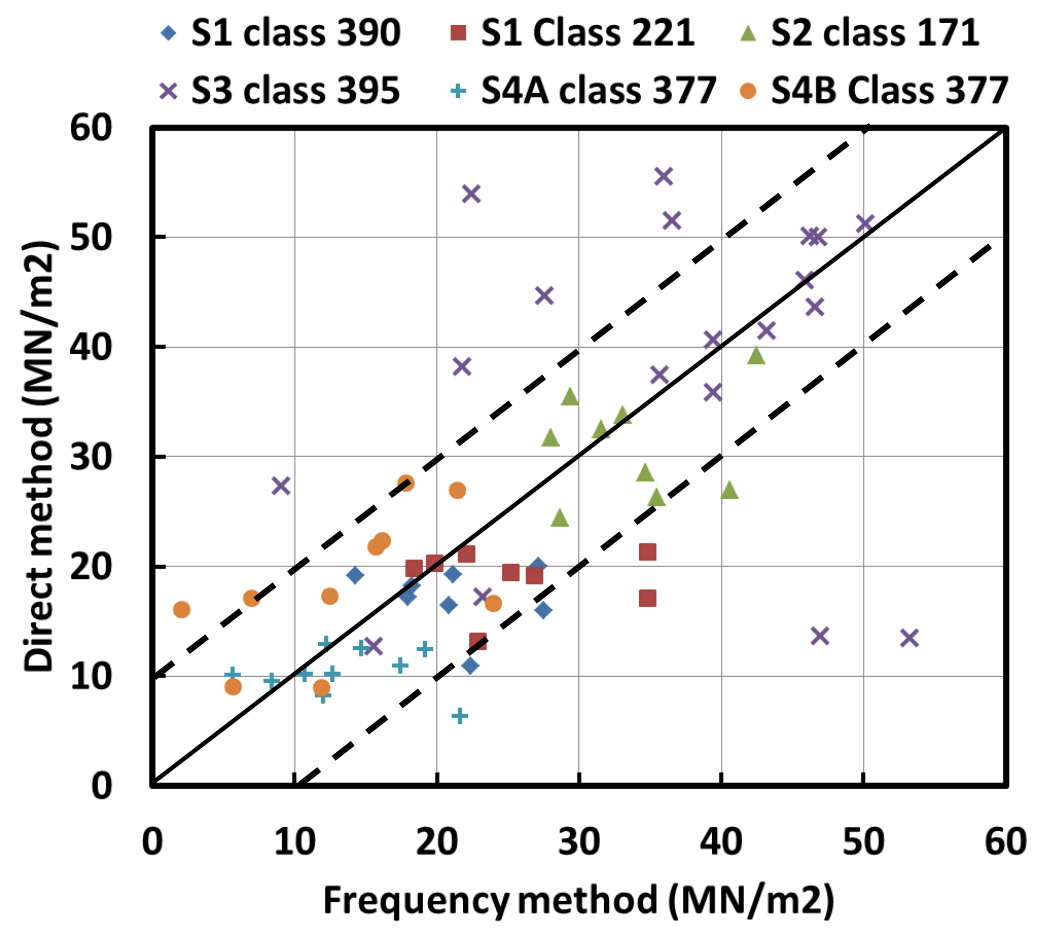

Figure 10. Comparison between system moduli found from direct and frequency methods at study sites

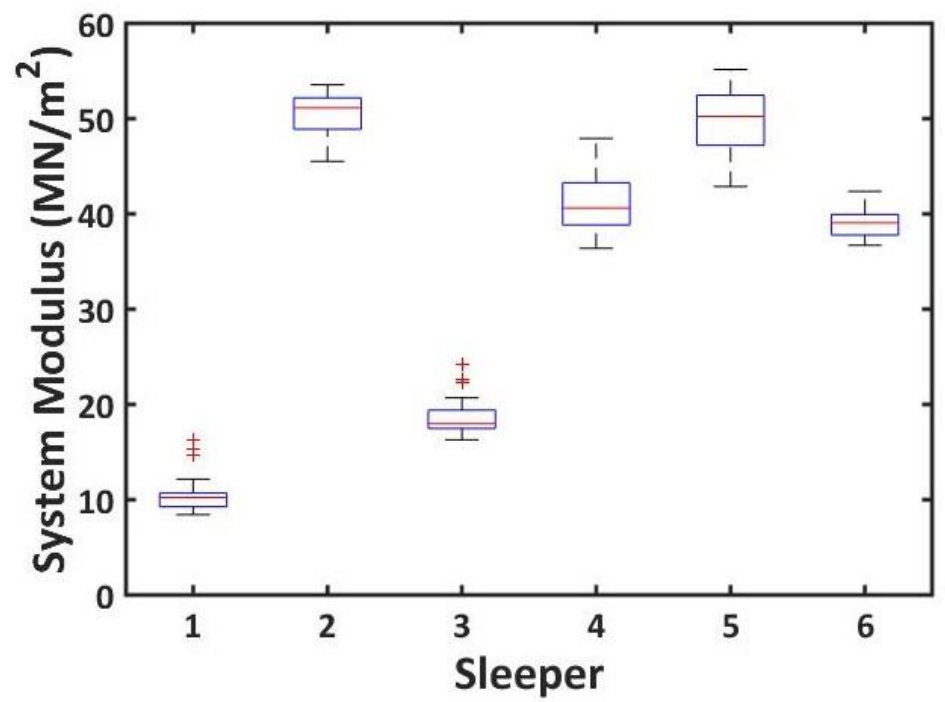

Figure 11. System modulus from site 3 for first 6 sleepers 